\title{
Ground-based radio observations to probe the ozone content in the meteor region
}

\author{
Giordano Cevolani $\left({ }^{1}\right)$ and Giuseppe Pupillo $\left({ }^{2}\right)\left({ }^{3}\right)$ \\ ( $\left.^{1}\right)$ Istituto di Scienze dell'Atmosfera e del Clima (ISAC), CNR, Bologna, Italy \\ ${ }^{2}$ ) Dipartimento di Elettronica e Telecomunicazioni (DET), Università di Firenze, Italy \\ $\left({ }^{3}\right)$ Osservatorio Ambientale di Campi Salentina (LE), Italy
}

\begin{abstract}
Radar studies of the plasma irregularities produced by meteoroid ablation provide a powerful diagnostic probe of the Earth's atmosphere. This role is especially important as an inexpensive route for studying several atmospheric processes in comparison with other remote sensing techniques or satellite measurements. Ozone concentration has been indirectly measured in the upper mesosphere/lower thermosphere region by the BLM (Bologna-LecceModra) Forward Scatter (FS) meteor radar by the detection of meteoroids interacting with the Earth's atmosphere. Results of variations of mesospheric ozone concentration at different height levels and time scales were deduced in 1992-2000 from the cumulative duration distributions of overdense echoes. Data of the BLM radar obtained in the last millennium decade confirm the existence of a secondary ozone layer at atmospheric heights of 85-90 km and show a gradual yearly depletion of the ozone content, similarly to the decrease measured in the eighties by the Solar Mesosphere Explorer (SME) satellite throughout consecutive years (Rusch et al., 1990). Radio observations show in addition large seasonal variations at middle latitudes where the abundance at a secondary ozone maximum at $85-90 \mathrm{~km}$ is found to be as much as a factor of two higher in spring months than that in summer months.
\end{abstract}

Key words meteor - radar-ozone

\section{Introduction}

The interplanetary material which falls on the Earth each year is estimated to be between 150000 and 220000 t. Most of this material consists of dust but the interaction with the atmosphere of macroscopic bodies having not negligible dimensions and some of which reaching the ground, is quite frequent. Even when the cosmic bodies did not hit the ground, explosive events characterized by the production of great quantities of energy, spanning from some

Mailing address: Dr. Giordano Cevolani, Istituto di Scienze dell'Atmosfera e del Clima (ISAC), CNR, Via Gobetti 101, 40129 Bologna; e-mail: g.cevolani@isac.cnr.it tenths of a kiloton to some tens of megatons, can happen.

Meteoroids - a conspicuous part of the interplanetary matter - are natural impactors contributing to the low Earth space particulate environment. These objects are the products of a series of dynamical and physical processes involving the planetary sciences, because they are strictly connected to the evolution of the minor bodies of the Solar System, asteroids and comets.

Radar systems operating in the frequency range 2-100 $\mathrm{MHz}$ have been employed for general studies of meteoric ionisation both as probes of atmospheric aeronomy and dynamics or for astronomical information about meteoroids. In addition to advances in the dynamics of mean winds (Cevolani, 1992; Singer et al., 1994), solar-driven tidal behaviour (Portnyagin et al., 1994), planetary-scale disturbances (Cevolani, 1991), and atmospheric gravity wave/turbulence 
characteristics (Baggaley, 1999), radar studies are providing useful information on the ozone content in the meteor region (70-120 km) (Jones and Simek, 1995; Cevolani et al., 1999; Hajduk et al., 1999). One reason of considerable interest to atmospheric scientists for mesospheric and lowerthermospheric ozone is that the lifetime of ozone in this region is shorter than atmospheric transport timescales. A relatively simple photochemical model (not including transport) which includes all the relevant chemical reactions, should be thus able to fit the observed ozone. According to Allen et al. (1984), ozone in the terrestrial atmosphere between the stratopause $(50 \mathrm{~km})$ and the homopause $(100 \mathrm{~km})$ affects: i) the thermal structure and dynamics of the upper atmosphere and its state of ionization (particularly in the D region); ii) the chemical evolution of the whole atmosphere on geological times; iii) the upper stratospheric ozone layer and the evolution of the terrestrial ecosystem; iv) the clarity in long range evolution; and (v) the operations of low earth-orbit satellites).

\section{The BLM radar operation}

\subsection{Technique and observations}

The «Physics of the Middle Atmosphere and Meteoroids» group of the ISAC-CNR has constructed a Forward Scatter (FS) meteor radar system for the study of the atmosphere in the meteor region $(70-120 \mathrm{~km})$ and of the physical/ astronomical characteristics of meteoroids (fig. 1). The FS meteor radar utilises a continuous wave transmitting frequency at $42.7 \mathrm{MHz}$ and about $1 \mathrm{kw}$ mean power and the transmitting station at Budrio $\left(44.6^{\circ} \mathrm{N}\right)$ near Bologna and the receiving stations at Lecce $\left(40.3^{\circ} \mathrm{N}\right)$ in Southern Italy and Modra $\left(48.3^{\circ} \mathrm{N}\right)$ (Slovakia).

The advantages to use a FS meteor radar are (Cevolani et al., 1995a):

- The signal from a meteor trails usually decays much more slowly at oblique incidence than at the normal incidence of backscatter.

- The slower decay of forward scatter offers the possibility of using HF and VHF radars to examine the distribution at greater heights (up to $140 \mathrm{~km}$ ) than hitherto ('echo ceiling' effect).
- The persistence of the signal also facilitates the discrimination between factors contributing to the ionisation loss; of particular interest are chemical effects, which become apparent only in the longer enduring echoes.

Forward Scatter (FS) Continuous Wave (CW) meteor radar observations carried out during 1995-2000 over the two long baselines Bologna-Lecce and Bologna-Modra enabled us to investigate the structure of the main meteoroid streams and the sporadic background by the cumulative distributions versus durations of the recorded echoes.

During routine observations, ionoscatter, sporadic $E$ and propagation during periods of high sunspot activity via the $F_{2}$ layer, represent other sources of signals which must be removed in our statistics. Analysis in meteor scatter applications utilises the arrival rate of meteor trains exceeding a minimum signal threshold, to evaluate the effects of changing different link and system parameters. In addition to longer lasting signals with investigation of the chemistry of the atmosphere at meteor heights, other advantages in using a FS meteor scatter facility are narrower bandwidth with a consequent reduction in noise, low power requirements and relative immunity from ionospheric disturbances. Moreover, we can investigate accurately the effect of the ionosphere on radio waves with attenuation, which increases with increasing ionization and is inversely proportional to frequency squared; and a rotation of the plane of polarization, known as Faraday rotation. This rotation angle depends on the geometry of the Earth's magnetic field, the electron density and has a $1 / f_{2}$ dependence, becoming increasingly important as frequency decreases with severe effects at HF (only a modest influence at is expected at VHF as the frequency of our FS system).

Two distinct regimes exist in the detection of meteor trains by radar, these being the so-called underdense and overdense conditions. If the linear density of ionization is sufficiently low $\left(q \leq 10^{14} \mathrm{el} / \mathrm{m}\right)$, the train is said to be underdense with a corresponding duration of $T<1.5 \mathrm{~s}$ for a FS radar (Cevolani and Hajduk, 1993) and in this case the scattering is by the individual electrons which behave independently of one another. For $q \geq 10^{14} \mathrm{el} / \mathrm{m}$ the train is said to be overdense 


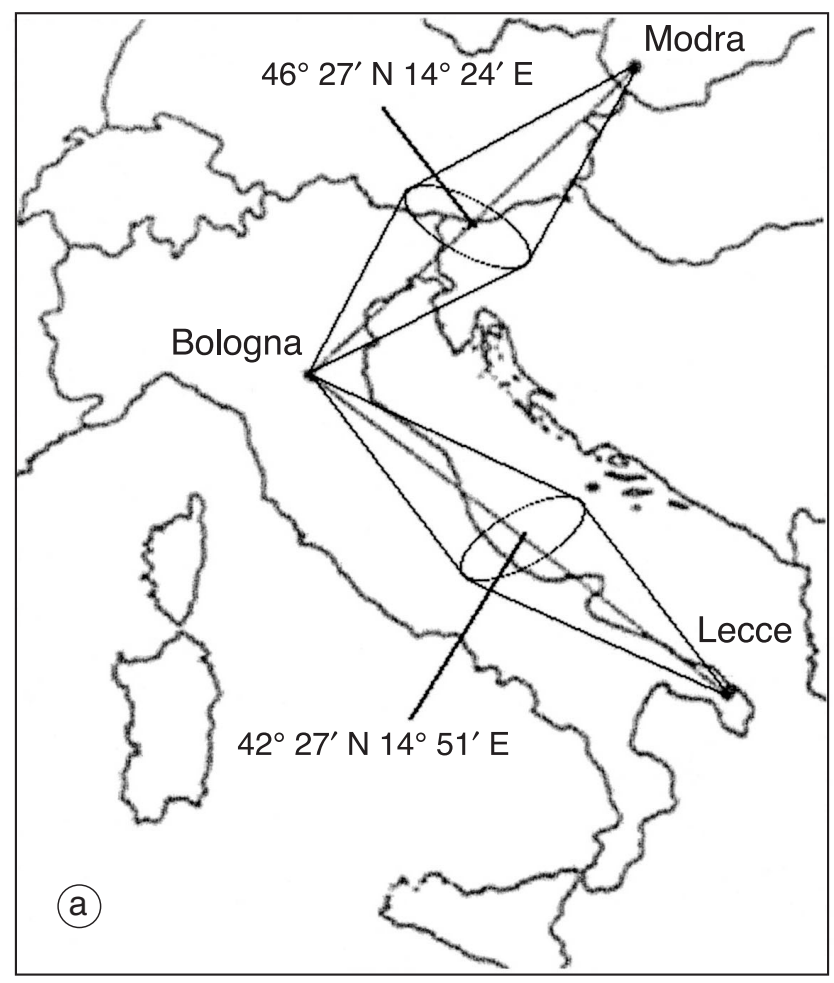

$(T \geq 1.5 \mathrm{~s})$ with the incident wave totally reflected as if the ionized channel was a metallic conducting cylinder. A simple calculation of the peak received power from a typical FS meteor echo indicates that most meteors with $q>5 \times 10^{12}$ $\mathrm{el} / \mathrm{m}$ will be detected by the system (Cevolani et al., 1995a,b).

Activity of main meteor showers and sporadic background which represents another complex of meteor echoes, has been observed by the BLM radar in the 1995-2000 years. Only the data from the central part of the shower activity with the hours of the radiant transit of any individual shower, are seen as the most representative for the mass-distribution of the meteor complexes. In order to determine more properly the period of the shower activity, attention was drawn to combined hourly distributions of echoes versus reflection time and versus echo durations to be utilized as an observational diagnostic tool of the presence in any individual meteoroid stream

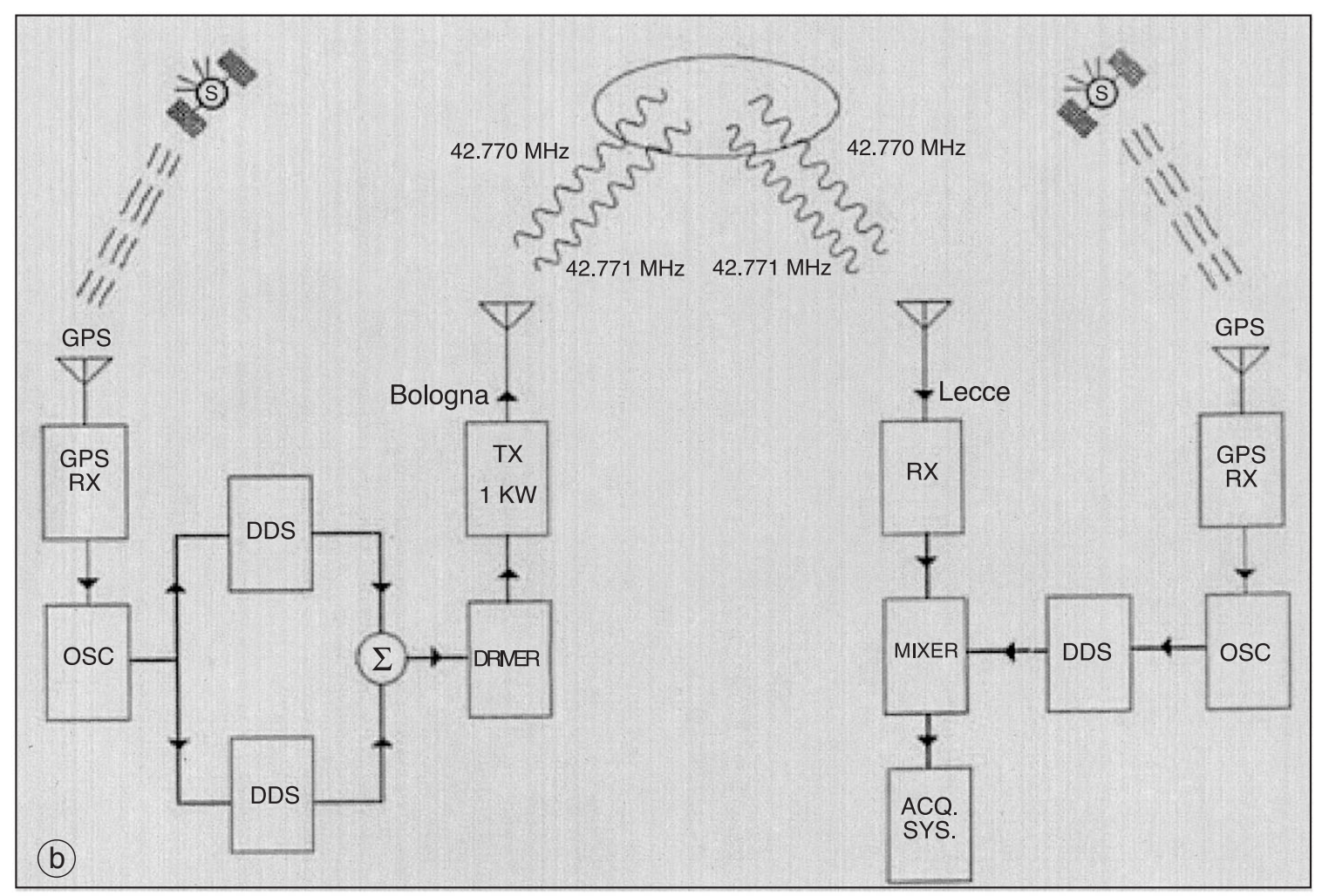

Fig. 1a,b. a) Geography of the BLM (Bologna-Lecce-Modra) Forward Scatter (FS) meteor radar (Cevolani et al., 1995b). The ovals represent the 'hot spots' (maximum concentration zones) of meteor trails detected by the radar; b) block-diagram of the FS system for the Bologna-Lecce baseline. 

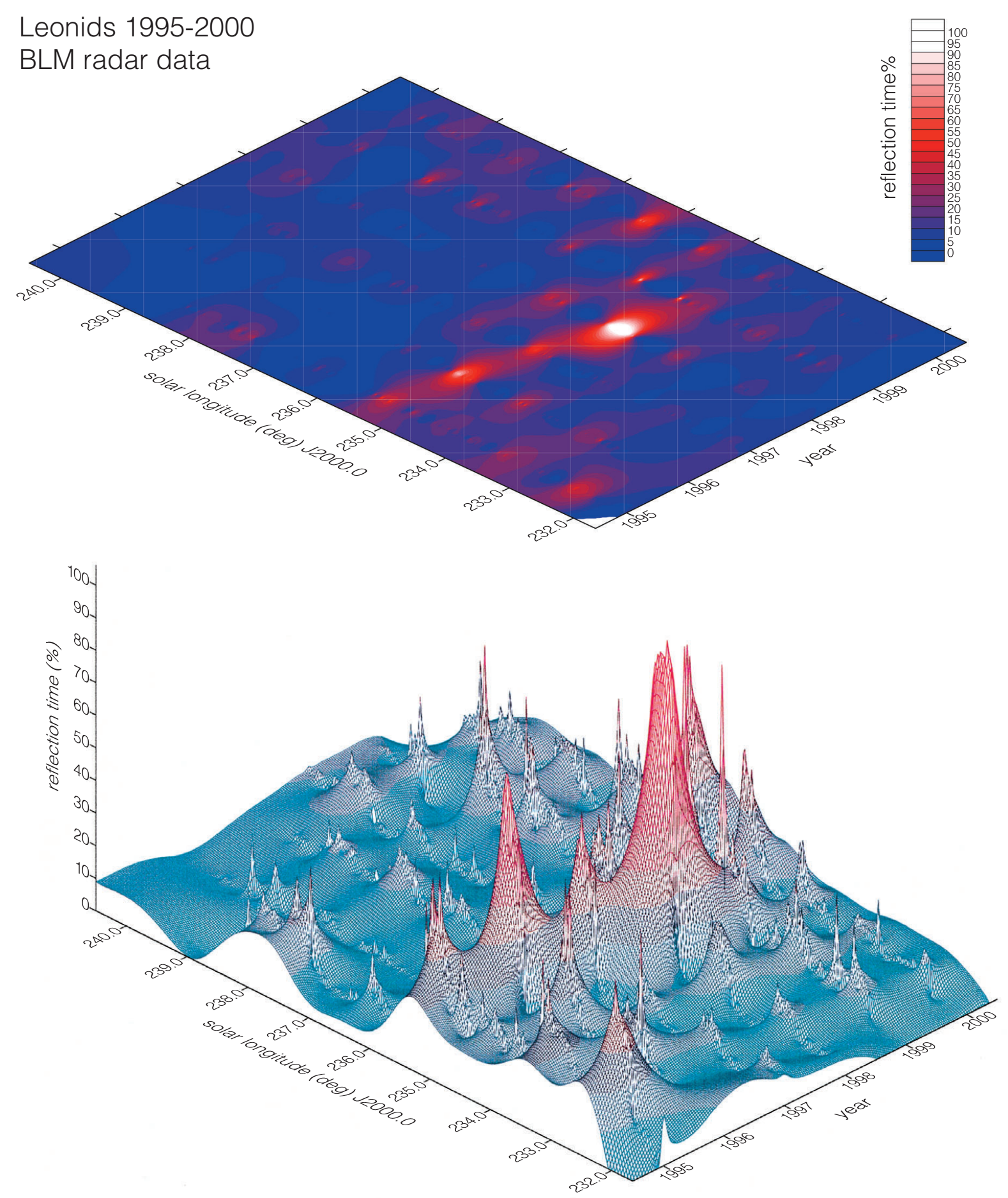

Fig. 2a. Activity of Leonids in the 1995-2000 period, in terms of reflection time (in percentage) of the BLM radioechoes (lower) and the relative section (upper) as a function of solar longitude (equinox J2000).

of distinct populations of particles with different masses, and moreover, of the existence of diffuse radiants. Correction factors and characteristics of the employed radio equipment probably influence the activity profile of different meteoroid streams. Our results show that the hourly rates of meteor echoes may be influenced by the changing angle between the meteor shower radiant and 
Geminids 1996-2000

reflection time (\%)

BLM radar data
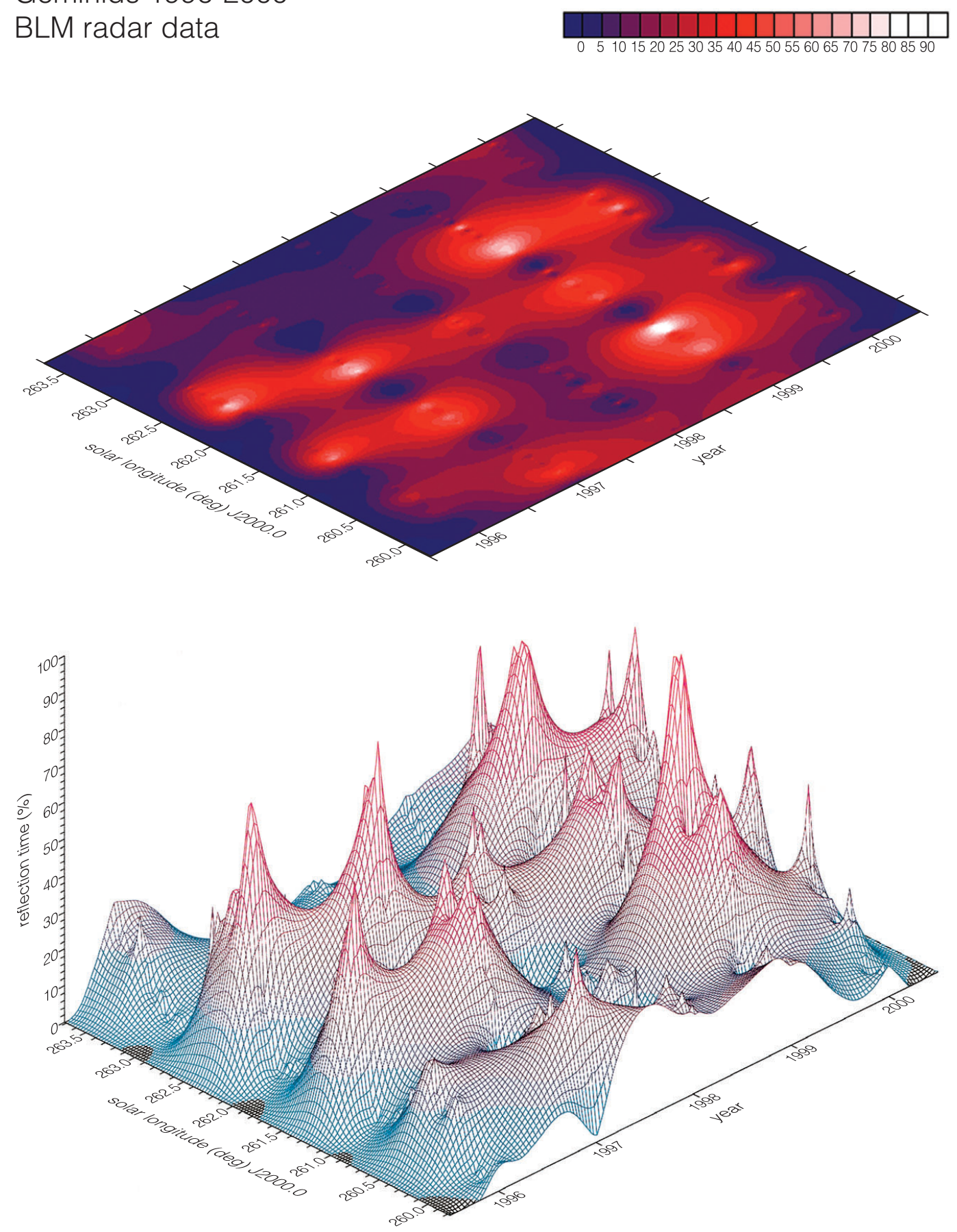

Fig. 2b. Activity of Geminids in the 1996-2000 period, in terms of reflection time (in percentage) of the BLM radioechoes (lower) and the relative section (upper) as a function of solar longitude (equinox J2000).

the antenna beam orientation (observability function).

Figure 2a,b shows the activity of (a) Leonids in the 1995-2000 years and (b) Geminids in the
1996-2000 years, in terms of reflection time (in percentage) of the BLM radioechoes (lower) and the relative section (upper) as a function of the solar longitude (equinox J2000). 
These data allow us to descriminate proper periods of high activity of the meteoroid stream, particularly rich in bright meteor (with long duration echoes).

\subsection{The mesospheric ozone and overdense meteors}

In the eighties, mesospheric ozone was systematically measured by near-infrared and ultraviolet spectrometers on the Solar Mesospheric Explorer (SME) during 5 years (December 1981-December 1986) (Rusch et al., 1990). These data confirmed the existence of a secondary ozone layer with about one order higher abundance of the ozone content at atmospheric heights of 80-90 km in comparison with its expected gradual decrease with height (Thomas, 1990). In addition, the SME results strongly supported earlier observations of a secondary peak in the ozone concentration at 83 $\mathrm{km}$ derived from ultraviolet light measurements during stellar occultations (Hays and Roble, 1973) or at $85 \mathrm{~km}$ derived from the ultraviolet solar radiation (Strobel, 1978). The Atmospheric Trace Molecule Spectroscopy (ATMOS) experiment (Gunson et al., 1990) returned observations of both mesospheric $\mathrm{H}_{2} \mathrm{O}$ and $\mathrm{O}_{3}$ up to $86 \mathrm{~km}$ altitude, showing large differences in the model and the observed abundances of mesospheric $\mathrm{O}_{3}$. Microwave $(1.2 \mathrm{~mm})$ spectral line observations of $\mathrm{O}_{3}$ exhibited 20-30\% larger mesospheric ozone abundances than indicated by the April $30^{\circ} \mathrm{N}$ average profiles from SME and $60-80 \%$ larger than reported in a photochemical model employing current photochemical rate constants (Clancy, 1994).

Measurements of mesospheric ozone above the stratopause $(50 \mathrm{~km})$ can be of great assistance to the larger program of stratospheric ozone research because high altitude ozone is affected by some of the same chemical cycles that are important in controlling stratospheric ozone (World Meteorological Organization, 1981). Since a smaller group of reactions is sufficient for describing the behaviour of mesospheric ozone there is an opportunity to test key parts of stratospheric models under the simplified conditions of the upper atmosphere.
The heights of the upper mesophere correspond to the lower part of the meteor zone (roughly 70-120 km) and especially to the end points of bright meteors or of maximum ionization points of the overdense meteor trains. The method to measure the ozone content in the meteor zone has been suggested by Jones et al. (1990). The decay of a radio echo from a train of ionisation caused by a meteor is determined by diffusion and for the longer lasting echoes by the loss of free electrons. Jones et al. (1990) have used the observation of meteor echo durations to obtain ozone concentrations in good agreement with those obtained by other methods; this leads the authors to conclude that meteor observations could provide a valuable method of monitoring ozone concentrations. The deficiency of longduration radar meteor echoes observed in the cumulative duration distribution by a distinct break (or 'knee') is thus due to the chemical reactions between meteoric ions and ozone, which cause a large decrease of the electron density of trains. According Jones and Simek (1995) the 'knee' effect is a consequence of the reaction of ozone with the meteoric ions. By analyzing our BLM radar data, we found an increase in the relative proportion of long-duration echoes from sporadic background in the daytime over comparable rates in the dark hours. The proportion of persistent echoes (with duration $T>10 \mathrm{~s}$ ) increases rapidly after sunrise at meteor heights (fig. 3).

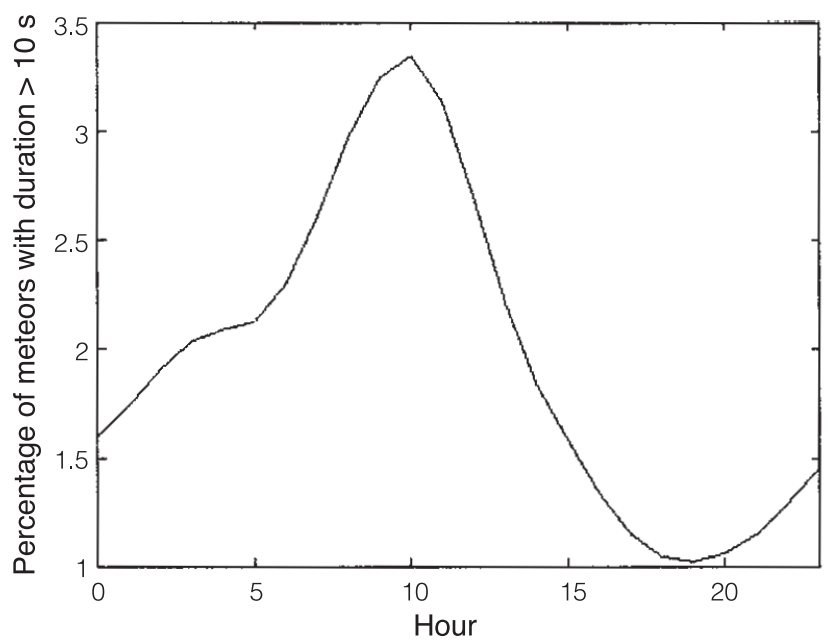

Fig. 3. Proportion of persistent BLM echoes (with duration $T>10 \mathrm{~s}$ ) from sporadic meteors in 1998 . 


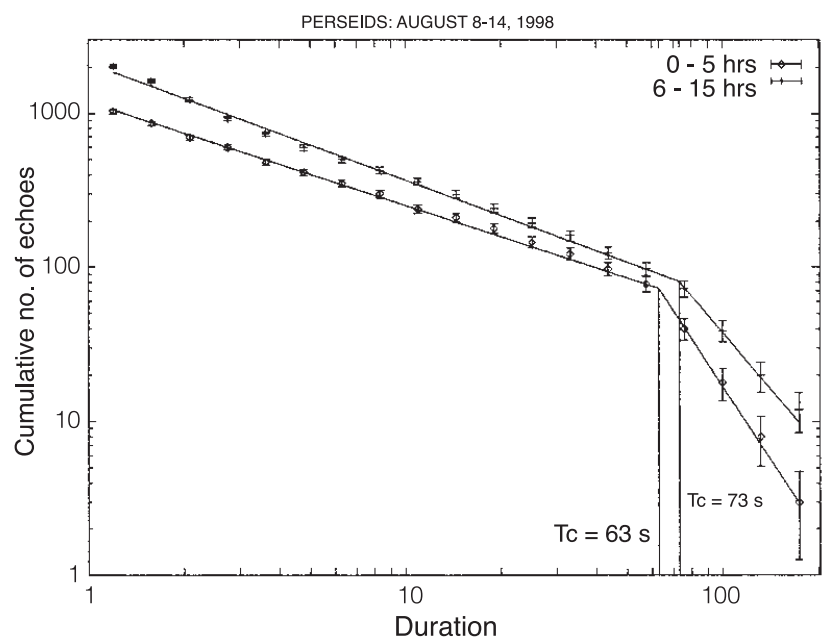

Fig. 4. Cumulative number of BLM echoes recorded during the Perseids 1998 (August 8-14) before and after sunrise at the mesopause level.

The gradual decrease of long duration echoes well before sunset may reflect the noon minimum in the ozone concentration. Ozone is rapidly dissociated by solar UV radiation and it should be possible to observe a rapid increase in $T$ after sunrise for meteor showers which transit close to dawn (fig. 4).

Figure 4 shows the cumulative number of echoes recorded during the Perseids 1998 (August $8-14$ ) before and after sunrise at $85-90 \mathrm{~km}$. Values of the critical time $T_{c}$ are effectively greater in the daytime with respect in the nightime hours at the mesopause level. This is in agreement with the opposite trend in the ozone variations with lower ozone concentrations during the daytime.

The break-time in the echo duration distributions at durations of $T_{c}$ corresponds to the observed change in different meteor showers from diffusion regime to the recombination regime in the meteor trail (fig. 5a-d). The ozone concentration corresponding to the knee is related to $T_{c}$ by

$$
\left[\mathrm{O}_{3}\right]=\left(\alpha T_{c}\right)^{-1}
$$

McIntosh and Hajduk (1977) have shown attachment to be unimportant for ionization loss in meteor trains. A comprensive study of the chemistry of the meteor region shows that dissociative recombination of the meteoric oxide ions produced by the oxidation of the meteoric ions by ozone is likely the most important process for the removal of ionization.

The loss of electrons is a two-step process:

1) the meteoric ions are oxidized by the ozone and the molecular oxygen

$$
\begin{gathered}
\mathrm{M}^{+}+\mathrm{O}_{3} \Rightarrow \mathrm{MO}^{+}+\mathrm{O}_{2} \quad\left(\alpha=2 \times 10^{-10} \mathrm{~cm}^{3} \mathrm{~s}^{-1}\right) \\
\mathrm{M}^{+}+\mathrm{O}_{2}+\mathrm{A} \Rightarrow \mathrm{MO}_{2}^{+}+\mathrm{A} \quad\left(\alpha=2.5 \times 10^{-30} \mathrm{~cm}^{3} \mathrm{~s}^{-1}\right),
\end{gathered}
$$

2) the oxide ions recombine dissociatively with electrons

$$
\begin{aligned}
& \mathrm{MO}^{+}+e^{-} \Rightarrow \mathrm{M}+\mathrm{O} \quad\left(\alpha=5 \times 10^{-7} \mathrm{~cm}^{3} \mathrm{~s}^{-1}\right) \\
& \mathrm{MO}_{2}^{+}+e^{-} \Rightarrow \mathrm{M}+\mathrm{O}_{2} \quad\left(\alpha=1.0 \times 10^{-6} \mathrm{~cm}^{3} \mathrm{~s}^{-1}\right)
\end{aligned}
$$

where $\mathrm{M}^{+}$is the meteoric ion and $\mathrm{A}$ is a neutral atmospheric molecule.

These two last reactions proceed very rapidly so that the rate of the combined process is limited by the oxidation process mainly due to the ozone.

Ozone concentrations versus altitude have been derived at mid-latitudes from radar meteor data and compared with various theoretical deductions (Noxon, 1975; Keating and Young, 1985; Sica, 1993; ). Radar estimates (BLM data; Jones et al., 1990) tend to be larger by a factor of about 2 than the mean theoretical values, which differ themselves by about the same factor in this region (fig. 6). Possibly the used values for the oxidation rate coefficient $\alpha$ in $\left[\mathrm{O}_{3}\right]=(\alpha T)^{-1}$ (where $T_{c}$ is the critical duration) is too low by a factor of 2 (Jones and Simek, 1995).

As regards the height determination, the time $T_{c}$ corresponding to the 'knee' in the echo duration distribution, provides a measure of the 'chemistry' time constant at an altitude corresponding approximately to the maximum luminosity of those meteors associated with the 'knee'. Hence, from simultaneous radar and visual observations of meteor showers with different velocities, it should be possible to determine how $T_{c}$ varies with height for any single meteor shower (Jones and Simek, 1995).

Changes in the structure of the secondary ozone maximum near $85-90 \mathrm{~km}$ are directly related to the April maximum (fig. 7). The large 

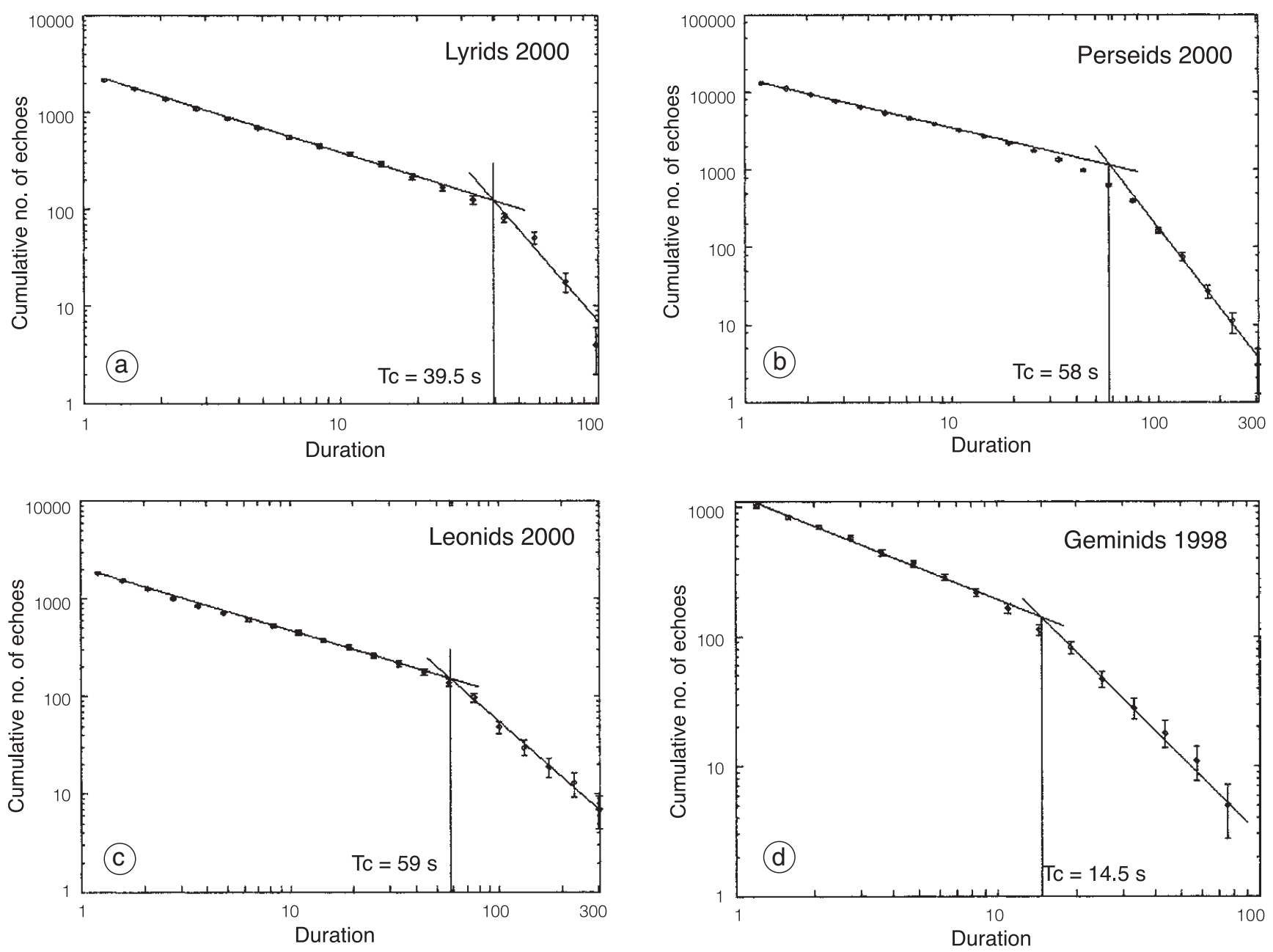

Fig. 5a-d. Cumulative number of BLM echo counts $N$ versus the observed echo duration $T$, relative to: a) Lyrids (21-22 April 1999); b) Perseids (12-13 August 1999); c) Leonids (17-18 November 1999); and (d) Geminids (12-13 December 1999). A time $T_{c}$ is adopted: echoes with durations greater than $T_{c}$ are predominantly 'chemistry-limited', while shorter-lasting echoes are diffusion limited.

scale annual and semiannual ozone variations at the mesopause level in the 1992-1998 years are dominant features in the ozone radar data (and satellite data as well; see, for instance, SME data). The observed changes are generally semiannual and these variations emphasize the importance of dynamical processes in the meteor region (Hajduk et al., 1999). Ozone will change as the atomic oxygen changes. Most of the atomic oxygen is produced in the lower thermosphere, varies seasonally with the solar radiation input, and is transported into the mesosphere by mixing and advection. Changes in the rate of diffusion and advection can modify mesospheric ozone in these ways: i) by changing the direct transport of odd oxygen from the thermospheric source region; and (ii) by modifying the transport of water vapor and hydrogen radical concentration that control its photochemical destruction (Clancy et al., 1994).

Seasonal variations of the meso-thermospheric ozone concentration have been deduced by different techniques. For instance, ozone concentration inferred from measurements of radiance at $1.27 \mu$ (Thomas, 1990) shows wide seasonal variations particularly at middle and high latitudes where the ozone abundance is found to be as much as a factor of three higher at the equinoxes as that at the solstice near 85 $\mathrm{km}$. Dynamical reasons related to seasonal va- 


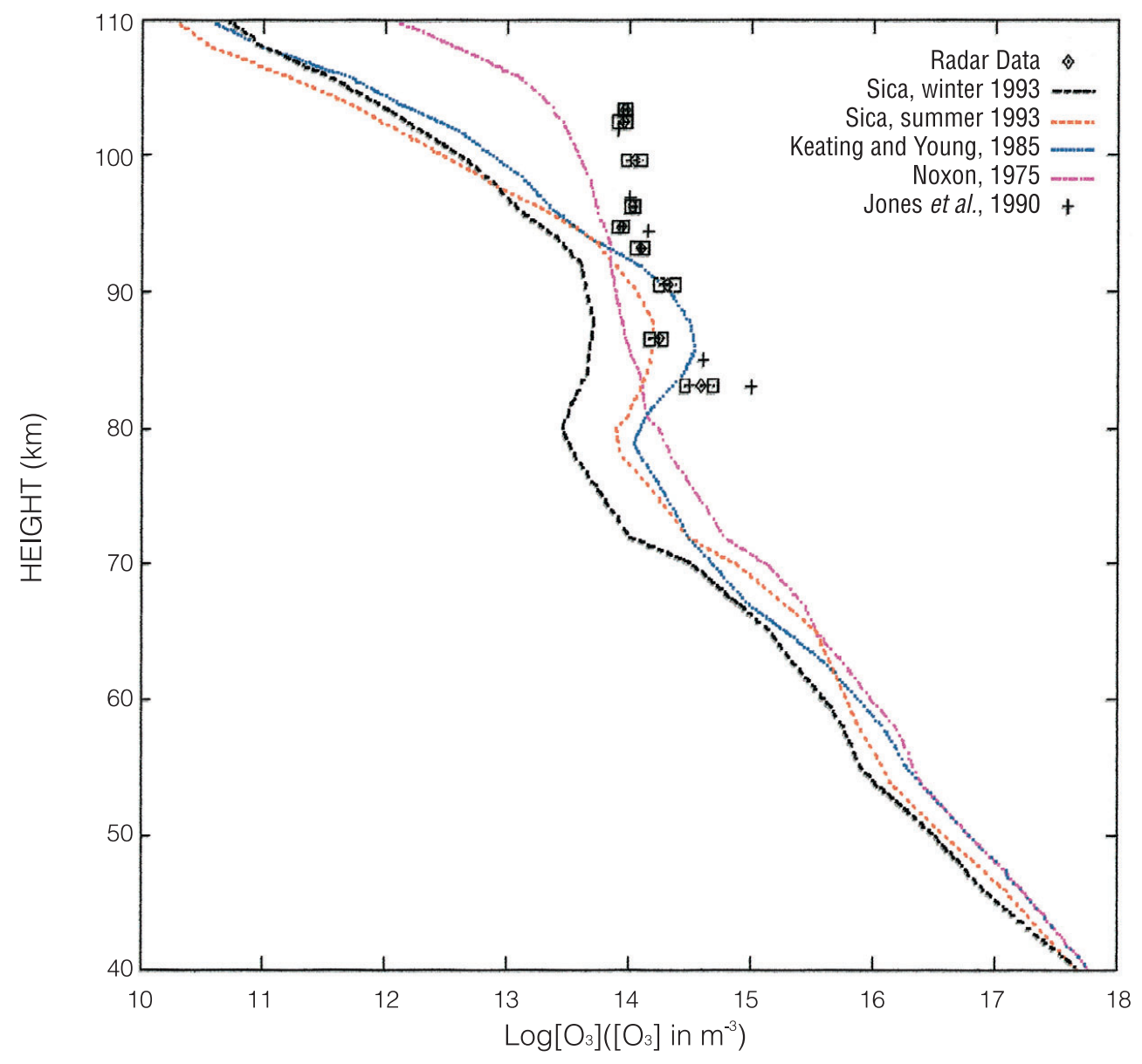

Fig. 6. The secondary maximum between 85 and $90 \mathrm{~km}$ in the ozone profile.

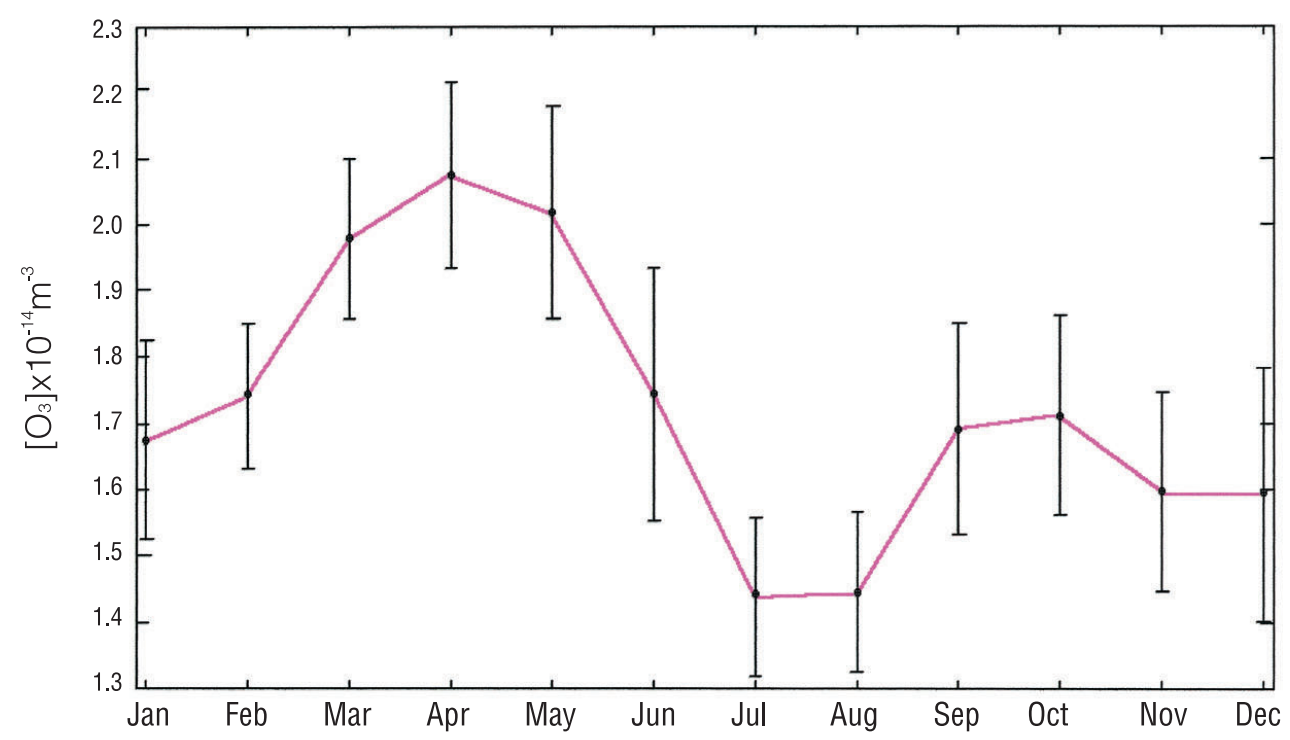

Fig. 7. Average seasonal trend of the ozone content near $85-90 \mathrm{~km}$ at $45^{\circ} \mathrm{N}$, derived in the $1992-1998$ years from the BLM radar echoes. 


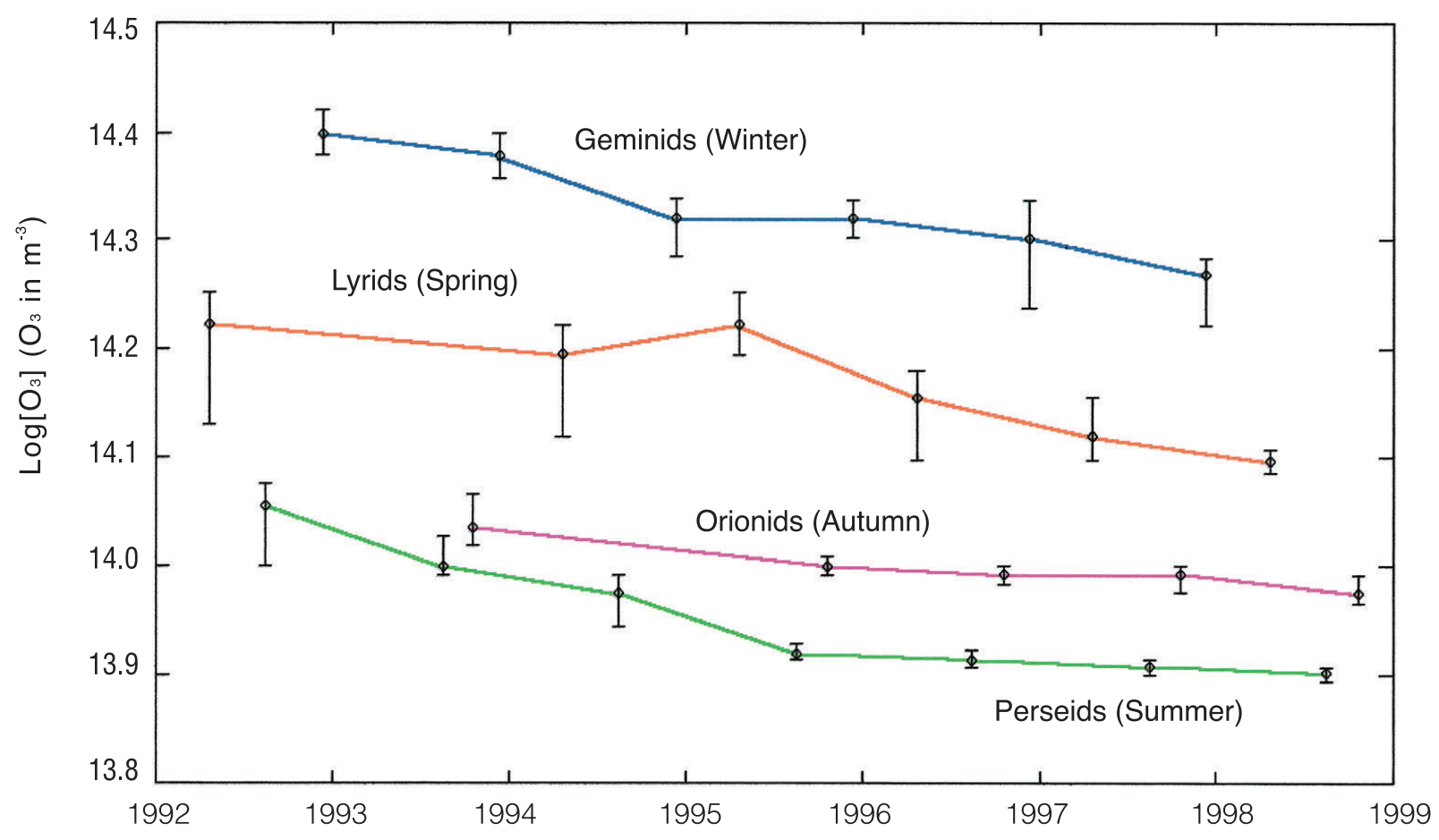

Fig. 8. Yearly ozone depletion near $85-90 \mathrm{~km}$ at $45^{\circ} \mathrm{N}$ derived in the $1992-98$ years from the BLM radar echoes.

riations in the propagation and dissipation of gravity waves have been suggested to account for these variations, so that mesospheric ozone density observations may provide a sensitive indicator of gravity wave effects in the middle atmosphere (Cevolani et al., 2000).

Observations of meteor showers - Lyrids, Perseids, Leonids and Geminids - are representative of the four different seasons. The yearly results of $\left[\mathrm{O}_{3}\right]$ give expressive results, suggesting a gradual decrease of the ozone concentrations in the secondary ozone layer in the 1992-1998 yearly period (fig. 8).

Due to the scarcity of data at the longest duration categories (long enduring echoes), the errors appear consistent, but the decreasing trend of $\left[\mathrm{O}_{3}\right]$ during the springtime observations in the same date of the Lyrid maximum (April 22) each year, can hardly be attributed to errors.

\section{Conclusions}

The BLM radar can indirectly measure mesospheric ozone concentrations which are complementary to those obtained by different techniques and methods at stratospheric altitudes. Investigation of the upper mesosphere ozone layer is still at the beginning stage and, at present, only an approximate approach is available by using this radar technique. The durations of radio meteors have been seen to be a valuable diagnostic for monitoring $\left[\mathrm{O}_{3}\right]$ in the meteor region, but the height information was extracted by an indirect procedure (maximum ionization heights for any meteor shower observed in different months). An interferometric heightfinding system would allow us in near future to measure the duration distribution as a function of the height and hence $\left[\mathrm{O}_{3}\right](\mathrm{h})$ could be measured on a continuous basis in the mesosphere and lower thermosphere.

Monitoring of the ozone content at the mesopause level (about $80 \mathrm{~km}$ ) is of prominent importance since there is a sharp drop in the ozone concentration near the mesopause possibly produced by the rapid increase in the destruction of water vapour (Vardavas et al., 1998). In addition, determination of mean nighttime-todaytime variations of the ozone concentration 
at different heights would be thus possible since some models (Connor et al., 1994) predict two peaks in the nighttime/daytime ratio, one near 75 $\mathrm{km}$ and the second one near $110 \mathrm{~km}$.

Wide seasonal variations pointed out near $85 \mathrm{~km}$ by satellite and radar data at middle latitudes and in coincidence of the secondary ozone maximum near $85 \mathrm{~km}$, are thought to be in connection to the activity of internal gravity waves of tropospheric origin (Thomas et al., 1984). This seasonal behaviour has important consequences for the distribution of chemical species. Breaking gravity waves are probably responsible for most of the momentum forcing that drives the mesospheric circulation and for the production of much of the turbulent mixing (eddy diffusion) found at mesospheric heights (Garcia and Solomon, 1985).

\section{REFERENCES}

ALLEN, M., J.I. LUNINE and Y.L. YUNG (1984): The vertical distribution of ozone in the mesosphere and lower thermosphere, J. Geophys. Res., 89, 4841-4872.

BAGGALEY, W.J. (1999): Using the AMOR facility to probe the atmosphere, in Meteoroids 1998, Tatranska Lomnica, August 17-21, 1998, edited by W.J. BAGGALEY and V. PORUBCAN, Astronomical Institute of SAV, 15-20.

Cevolani, G. (1991): Strato-Meso-Thermospheric coupling at mid-latitudes in the course of mid-winter stratwarming during DYANA, Geophys. Res. Lett., 18, 1987-1990.

Cevolani, G. (1992): Wind characteristics in the middle atmosphere during the DYANA campaign 1990, Bologna, Italy, Ann. Geophysicae, 10, 802-809.

Cevolani, G. and A. Hajduk (1993): Forward scatter observations of meteor showers, in Meteoroids and their Parent Bodies, Smolenice, Slovakia, July 6-12, 1992, edited by J. STOHL and I.P. WiLliams, Astronomical Institute of SAV, 253-256.

Cevolani, G., G. Bortolotti, C. Franceschi, G. Grassi, G. TRIVELlONE, A. HAJduK and S.P. KingSLEY (1995a): The Bologna-Lecce forward scatter radar experiment: preliminary results, Planet. Space Sci., 43, 765-772.

Cevolani, G., G. Bortolotti, L. Foschini, C. Franceschi, G. GRASSI, G. TRIVEllone, A. HAJDUK and V. PORUBCAN (1995b): Radar observations of the Geminid meteoroid stream, Earth, Moon and Planets, 68, 247-255.

Cevolani, G., A. Hajduk, M. Hajdukovà, V. PorubCan and G. TRIVELLONE (1999): Ozone concentration at meteor heights determined from forward-scatter radar echoes, J. Atmos. Terr. Phys., 61, 539-543.

Cevolani, G., M. Ciarlatani, A. Hajduk, V. Porubcan and G. PUPILLO (2000): Ground-based radio observations of ozone in the upper mesosphere/lower thermosphere, EGS XXV General Assembly, Nice, France, 25-29 April 2000, Geophys. Res. Abstr., 2, ST10.

Clancy, R.T., B.J. SANDOR and D.W. Rusch (1994): Microwave observations and modelling of $\mathrm{O}_{3}, \mathrm{H}_{2} \mathrm{O}$, and $\mathrm{HO}_{2}$ in the mesosphere, J. Geophys. Res., 99, 5465-5473.

Connor, B.J., D.E. Siskind, J.J. Tsou, A. PARrish and E.E. REMSBERG (1994): Ground-based microwave observations of ozone in the upper stratosphere and mesosphere, J. Geophys. Res., 99, 16757-16770.

GARCIA, R.R. and S. SOlOMON (1985): The effect of breaking gravity waves on the dynamics and chemical composition of the mesosphere and lower thermosphere, J. Geophys. Res., 90, 3850-3868.

Gunson, M.R., C.B. FARMER, R.H. NORTON, R. ZANDER, C.P. Rinsland, J.H. SHAW and B.C. GAO (1990): Measurements of $\mathrm{CH}_{4}, \mathrm{H}_{2} \mathrm{O}, \mathrm{CO}, \mathrm{HO}_{2}$ and $\mathrm{O}_{3}$ in the middle atmosphere by the atmospheric trace molecule spectroscopy experiment on spacelab 3, J. Geophys. Res., 95, 13,867-13,882.

Hajduk, A., M. Hajdukova, V. PorubCan, G. CEVOlani and G.GRASSI (1999): The ozone concentration in the meteor zone, in Meteoroids 1998, Tatranska Lomnica, August 17-21, 1998, edited by W.J. BAGGALEY and V. PORUBCAN, Astronomical Institute of SAV, 91-97.

HAYS, P.B. and R.G. RoBle (1973): Observations of mesospheric ozone at low latitudes, Planet. Space Sci., 21, 273-279.

Jones, J., B.A. McInTOSH and M. SIMEK (1990): Ozone and the duration of overdense radio meteors, J. Atmos. Terr. Phys., 52, 253-258

JONES, J. and M. SIMEK (1995): A note on the determination of ozone concentrations from radio-meteor duration distributions, Earth, Moon and Planets, 68, 329-338

KEATING, G.M. and D.F. YounG (1985): Interim reference ozone models for the middle atmosphere, Handbook for MAP 16, edited by K. LABITZKE, J.J. BARNETT and B. EDWARDS, pp. 205.

MCINTOSH, B.A. and A. HAJDUK (1977): Sunrise effect on persistent radar echoes from sporadic meteors, Bull. Astron. Inst. Czechosl., 28, 280-285.

NoxON, J.F. (1975): Twilight enhancement in $\mathrm{O}_{2}$ airglow emission, J. Geophys. Res., 80, 1370-1373.

NoxON, J.F. (1982): A global study of $\mathrm{O}_{2}$ airglow: day and twilight, Planet. Space. Sci., 30, 545-557.

PorTNYAGIN, Y.A., G.CEVOLANI,E.KAZIMIROVSKY,G.KOKIN, A. MANSON, H. MulleR, Y. PORTNIAGYN, R. SCHMindeR and W. SINGER (1994): Mean wind characteristics of the middle atmosphere during the DYANA campaign, part II, J. Atmos. Terr. Phys., 56, 1731-1752.

Rusch, D.W, T. ClanCy, M.P. MCCORMICK and G.M. ZAWODNY (1990): A comparison of solar mesosphere explorer and stratosphere aerosol and gas experiment II ozone densities near the stratopause, J. Geophys. Res., 95, 3533-3537.

SiCA, R.J. (1993): Inferring middle atmospheric ozone height profiles from ground based measurements of molecular oxygen emission rates, J. Geophys. Res., 98, 1057-1067.

Singer, W., G.Cevolani, E. Kazimirovsky, G. Kokin, 
A. Manson, H. Muller, Y. Portniagyn and R. SCHMINDER (1994): Mean wind characteristics of the middle atmosphere during the DYANA campaign, part I, J. Atmos. Terr. Phys., 56, 1717-1729.

STROBEL, D.F. (1978): Parametrization of the atmospheric heating rate from 15 to $120 \mathrm{~km}$ due to $\mathrm{O}_{2}$ and $\mathrm{O}_{3}$ absorption of solar radiation, J. Geophys. Res., 83, 6225-6230.

THOMAS, R.J. (1990): Seasonal ozone variations in the upper mesophere, J. Geophys. Res., 95, 7395-7401.

Thomas, R.J., C.A. BARTH and S. SOLOMON (1984):
Seasonal variations of ozone in the upper atmosphere and gravity waves, Geopys. Res. Lett., 11, 673-676.

VARDAVAS, M., J.H. CARVER and F.W. TAYLOR (1998): The role of water-vapour photodissociation on the formation of a deep minimum in mesopause ozone, Ann. Geophysicae, 16, 189-196.

World Meteorological Organization (1981): The stratosphere 1981: theory and measurements, Rep. 11, WMO Global Ozone Research and Monitoring Project, Geneva, Switzerland. 